\title{
Comprehensive

\section{Bacterial Pathogens and Resistance Patterns in Children With Community-Acquired Urinary Tract Infection: A Cross Sectional Study}

\author{
Shahla Afsharpaiman ${ }^{1}$, Fatemeh Bairaghdar ${ }^{2}$, Mohammad Torkaman ${ }^{3}$, Zohreh Kavehm- \\ anesh ${ }^{4 *}$, Suzan Amirsalari ${ }^{2}$, Mehran Moradi ${ }^{5}$, Mohammad Javad Safavimirmahalleh ${ }^{5}$ \\ ${ }^{1}$ Health Research Center, Baqiyatallah University of Medical Sciences, Tehran, IR Iran \\ 2 Department of Pediatric Nephrology, Pediatrics Center, Baqiyatallah University of Medical Sciences, Tehran, IR Iran \\ ${ }^{3}$ Department of Neurology, Pediatrics Center, Baqiyatallah University of Medical Sciences, Tehran, IR Iran \\ ${ }^{4}$ Department of Pediatrics Gastroenterology, Pediatrics Center, Baqiyatallah University of Medical Sciences, Tehran, IR Iran \\ ${ }^{5}$ Medical Student, Baqiyatallah University of Medical Sciences, Tehran, IR Iran
}

\begin{tabular}{l}
\hline A R T I C L E I N F O \\
\hline Article type: \\
Original Article \\
\hline Article history: \\
Received: 20 Oct 2011 \\
Revised: 30 Oct 2011 \\
Accepted: 04 Nov 2011 \\
\hline
\end{tabular}

Keywords:

Urinary Tract Infections

Child

Drug Resistance

Bacteria

\begin{abstract}
A B S T R A C T
Background: Recent studies on bacterial pathogens causing urinary tract infection (UTI) in children have shown high levels of antibiotic resistance in clinical settings. objectives: We determined the common bacterial pathogens causing UTI and their antimicrobial resistance patterns in Iranian children.

Patients and Methods: The study subjects were 114 children (female subjects, 58.8\%) with culture-proven UTI categorized in the following 3 age groups: neonates ( $<28$ days, $\mathrm{n}=45$ ), infants ( 28 days to 2 years, $\mathrm{n}=41$ ), and children $(>2$ years, $\mathrm{n}=28$ ). Sensitivity testing was performed using the disc diffusion technique.

Results: The most frequently cultured pathogens included Escherichia coli (71.7\%) and Enterobacter (28.9\%). UTI caused by Enterobacter was more commonly detected in neonates $(60.6 \%)$ than in infants (21.2\%) and children (18.2\%). Imipenem was the most active agent against E. coli isolates (susceptibility, 97.3\%), followed by ciprofloxacin (90.4\%) and amikacin (82.9\%). Trimethoprim-sulfamethoxazole, cefalotine, and cephalexin were the least active agents, with $76.3 \%, 75.0 \%$, and $73.7 \%$ of E. coli isolates exhibiting resistance, respectively. Imipenem and ceftizoxime were the most effective antimicrobial agents against Enterobacter, with sensitivity rates of $85.2 \%$ and $71.4 \%$, respectively. Nitrofurantoin, ceftazidime, and cefalotine were the least active antimicrobial agents against Enterobacter, with resistance rates of $92.3 \%, 66.7 \%$, and $62.5 \%$, respectively.

Conclusions: The low susceptibility of common UTI pathogens to cephalosporins may be because of their high rate of administration to children with UTI in our population. A change in empiric therapy should be considered, especially in neonates.
\end{abstract}

Implication for health policy/practice/research/medical education:

Most of the recent studies, on antimicrobial susceptibility of bacterial pathogens causing UTI in children showed high levels of resistance to antibiotics. The present study determined the common types of bacterial pathogen causing UTI in children and their antimicrobial resistance patterns at a sample of Iranian children. Our results could be useful for pediatrician, children nephrologists, and infection diseases specialists.

\footnotetext{
* Corresponding author: Zohreh Kavehmanesh, Department of Pediatrics Gastroenterology, Pediatrics Center, Baqiyatallah University of Medical Sciences, Tehran, IR Iran. Tel:+98-2188214881, +98-2188603574,E-mail: z_kaveh@hotmail.com

DOI: $10.17795 /$ compreped-7078

(C) 2012 Iranian Society of Pediatrics.

This is an Open Access article distributed under the terms of the Creative Commons Attribution License (http://creativecommons.org/licenses/by/3.0), which permits unrestricted use, distribution, and reproduction in any medium, provided the original work is properly cited.
} 
- Please cite this paper as:

Afsharpaiman S, Bairaghdar F, Torkaman M, Kavehmanesh Z, Amirsalari S, Moradi M, Safavimirmahalleh MJ. Bacterial Pathogens and Resistance Patterns in Children With Community-Acquired Urinary Tract Infection: A Cross Sectional Study.J Compr Ped. 2012;3(1):1620. DOI: 10.17795/compreped-7078

\section{Background}

Urinary tract infection (UTI) is of great clinical importance owing to considerably high morbidity and mortality rates among children. Effective antimicrobial therapy for UTI is important and can reduce adverse events in this age group. Most recent studies, particularly in developing countries, on the antimicrobial susceptibility of bacterial pathogens causing UTI in children have shown high levels of antibiotic resistance in clinical settings (14). Some population-based surveys in North and Latin America have shown that resistance to commonly used antibiotics, such as trimethoprim-sulfamethoxazole, has doubled in uropathogens (5). Similar studies on young Iranian children with UTI have also revealed markedly high resistance to commonly used antibiotics, such as vancomycin, cloxacillin, amoxicillin, and some cephalosporin subgroups (6). In addition, it was suggested that the prevalence of antimicrobial resistance in young children with UTI is dramatically increasing and varies among different geographical and regional locations and various socioeconomic statuses (7). Increased antibiotic resistance is related to a variety of risk factors, including prior antibiotic exposure, urinary malformations, and the use of prophylactic antibiotics (8-10).

Owing to the slightly higher prevalence of UTI in our population compared to other developing countries (11) and the higher rate of congenital anomalies predisposing Iranian children to UTI (12), it is necessary to identify the bacterial agents responsible for UTI and to determine their sensitivity to antibiotics in our child population.

\section{Objectives}

The present study was designed to determine the common bacterial pathogens causing UTI and their antimicrobial resistance patterns in Iranian children.

\section{Patients and Methods}

This research is a cross sectional study on 114 children with culture-proven UTI treated in the pediatric ward of Najmieh hospital in Tehran over a 3-year period. The sampling strategy was convenient method. We didn't check normal assumption. The study plan was approved by the scientific and ethic committee of Baqiyatallah University of Medical Sciences and there are no conflict in treatment of patients during the study. The subjects were classified into 3 age groups: neonates ( $<28$ days, $n=45)$, infants ( 28 days to 2 years, $n=41$ ), and children $(>2$ years, $n=28$ ). Cultures were obtained from midstream-collected urine by using the suprapubic method in infants and small children and by the midstream method in toilet-trained children. Antibiotic sensitivity was tested using the disc diffusion technique (Kirby-Bauer's technique) by using various antibiotic discs according to National Committee for Clinical Laboratory Standards (13). Susceptibility to the following drugs was tested: amikacin, ceftriaxone, ceftizoxime, trimethoprim-sulfamethoxazole, cefotaxime, imipenem, cephalexin, gentamicin, cefalotine, chloramphenicol, nalidixic acid, cefixime, ceftazidime, and nitrofurantoin. A urine culture was considered positive when it resulted in one or more colony from a urine specimen collected by the suprapubic method and greater than or equal to 100,000 colonies by the midstream method in children with febrile disease or urinary symptoms. For statistical analysis, organisms with intermediate susceptibility were considered resistant. A renal ultrasonogram was also obtained for all studied patients to identify or rule out urinary malformations.

The quantitative data's distribution was checked by K-S and the differences and association was analyzed by using Chi2 and exact fisher test for qualitative data and Steudent T-test and Mann Whitney-U for quantitative data. All statistical analyses were performed using SPSS version 15.0 (SPSS Inc., Chicago, IL, USA). $P \leq 0.05$ was considered statistically significant.

\section{Results}

Among the studied infants and children, 40 (58.8\%) were girls and 29 (41.2\%) were boys. Boys were significantly younger than girls, and so, 34 (76.6\% ) of boys and only $11(23.4 \%)$ of girls were categorized in the neonate group ( $P<0.001$, OR: 21.09, 95\% CI: 7.96-55.86) (Figure 1). Patients had a mean erythrocyte sedimentation rate (ESR) of 38.96 $\pm 3.95 \mathrm{~mm} / \mathrm{h}$ and a mean white blood cell (WBC) count of $12,403.57 \pm 5,233.60 \mu \mathrm{mol} / \mathrm{L}$. The most frequently cultured pathogens included Escherichia coli 81 (71.7\%) and Enterobacter 33 (28.9\%). However, the frequency of these pathogens significantly differed across the 3 age groups. Specifically, the incidence of E. coli was higher in infants and children, and Enterobacter was more frequent in neonates than in the other groups (Figure 2). There were no significant differences between boys and girls in the frequency of cultured E. coli (61.7\% vs. 77.6\%) or Enterobacter (38.3\% versus $22.4 \%$ ). The antimicrobial susceptibility of the studied isolates is shown in Table 1. Imipenem was the most active agent against E. coli isolates (susceptibility, 97.3\%), followed by ciprofloxacin (90.4\%) and amikacin (82.9\%). Trimethoprim-sulfamethoxazole, cefalotine, and cephalexin were the least effective agents, with $76.3 \%$, $75.0 \%$, and $73.7 \%$ of $E$. coli isolates exhibiting resistance, 
respectively. Imipenem and ceftizoxime were the most efficient antimicrobial agents against Enterobacter, with sensitivity rates of $85.2 \%$ and $71.4 \%$, respectively. Nitrofurantoin, ceftazidime, and cefalotine were the least active agents against Enterobacter, with resistance rates of $92.3 \%$, $66.7 \%$, and 62.5\%, respectively. Compared to E. coli, Entero-

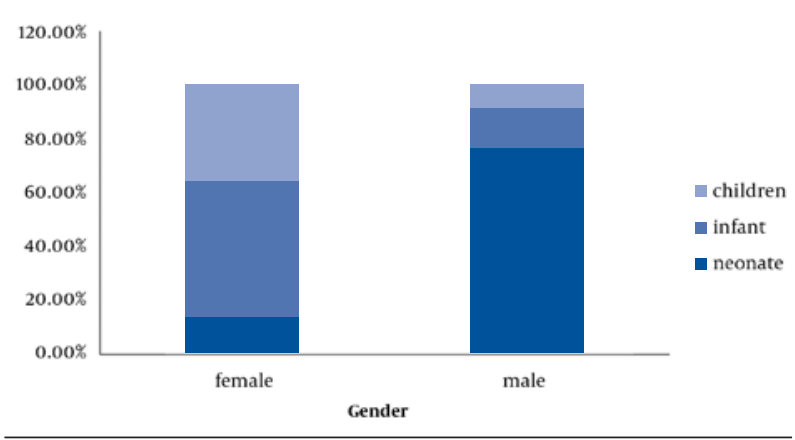

Figure 1. Sex and Age Distribution of the Subjects in this Study

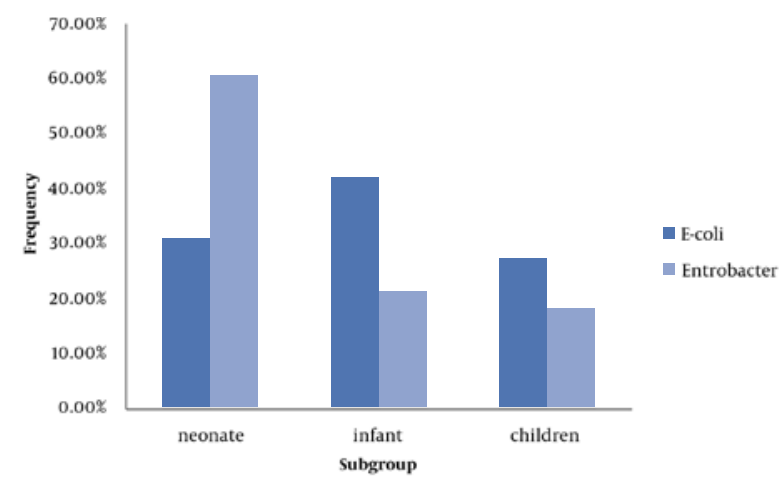

Figure 2. Incidence of Escherichia coli and Enterobacter Isolates in the Subgroups of Neonates, Infants, and Children bacter had a higher resistance rate to ceftazidime, amikacin, imipenem, gentamicin, and nitrofurantoin (Table 1). However, E. coli had higher resistance rates to cephalexin and trimethoprim-sulfamethoxazole than Enterobacter. Ninety-six patients (84.2\%) had normal renal-bladder ultrasonograms. In the other cases, bladder ultrasonograms showed abnormalities, including bladder wall thickness, bladder wall irregularity, and residual urine. The frequencies of these abnormalities were comparable in boys and girls $(12.8 \%$ vs. $17.9 \%, P=0.458)$.

\section{Discussion}

In the present study, the most frequently detected pathogen among children with UTI was E. coli $(71.7 \%)$, followed by Enterobacter (28.9\%). The frequency of E. coli infection is similar to that in previous reports from different regions of Iran and other developing countries. E. coli is the leading uropathogen and was isolated from 56.6$84.6 \%$ of Iranian children with febrile UTI $(6,11,14,15)$; this isolation rate had a wider spectrum in other countries, ranging from $37.3 \%$ (2) to $87.0 \%$ (4). Furthermore, the frequency of Enterobacter isolation in this study differed considerably from that of other similar surveys that isolated Enterobacter from urine cultures in only $2.3 \%$ to $3.7 \%$ of Iranian children with UTI $(6,14)$. Previous studies identified Enterobacteriaceae as the predominant pathogen in children with UTI (16-18). Similar to the findings of other studies, we more commonly isolated Enterobacter in neonates with UTI (44.4\%) than in infants (17.1\%) and children (21.4\%). This higher incidence of Enterobacter infection may be due to hospitalization of neonates, especially in neonatal intensive care units (19).

Although boys in this study were significantly younger than girls, the frequencies of positive urine cultures were similar between the 2 groups. Farajnia et al. reported that

\begin{tabular}{|c|c|c|c|}
\hline Antibiotics & Escherichia Coli, $(n=81)$ & Enterobacter, $(\mathbf{n}=33)$ & Pvalue \\
\hline \multicolumn{4}{|l|}{ Cephalosporin No. (\%) } \\
\hline Cefotaxime & $19(24.1)$ & $30(29.4)$ & 0.557 \\
\hline Ceftriaxone & $20(25.0)$ & $14(41.4)$ & 0.082 \\
\hline Ceftizoxime & $18(22.6)$ & $9(28.6)$ & 0.458 \\
\hline Cephalexin & $59(73.7)$ & $11(33.3)$ & $<0.001$ \\
\hline Cefalotine & $61(75.0)$ & $20(62.5)$ & 0.181 \\
\hline Cefixime & $22(27.9)$ & $14(42.9)$ & 0.120 \\
\hline Ceftazidime & $21(25.6)$ & $22(66.7)$ & $<0.001$ \\
\hline \multicolumn{4}{|l|}{ Others, No. (\%) } \\
\hline Amikacin & $13(17.1)$ & $14(41.9)$ & 0.005 \\
\hline Trimethoprim-sulfamethoxazole & $62(76.3)$ & $18(55.2)$ & 0.026 \\
\hline Imipenem & $2(2.7)$ & $5(14.8)$ & 0.015 \\
\hline Gentamicin & $19(23.4)$ & $17(53.3)$ & 0.002 \\
\hline Chloramphenicol & $28(35.0)$ & $16(50.0)$ & 0.137 \\
\hline Nalidixic acid & $31(38.4)$ & $11(33.3)$ & 0.609 \\
\hline Nitrofurantoin & $30(37.2)$ & $30(92.3)$ & $<0.001$ \\
\hline
\end{tabular}


the rate of positive cultures was nearly 2 times higher in females than in males (15). The male to female ratio in a report by Sharifian et al. was 1:2 (14). In other studies, UTI occurred in 1.5 to 5 times as many males as females during the neonatal period (20-22). Gender-specific differences in the rates of UTI may depend on the age. Boys are more commonly infected during the first 3 months of life, and after the first year, symptomatic UTI is more frequent among girls. Similarly, asymptomatic bacteriuria is more frequently detected in boys than in girls during the first 12 months of life. Thereafter, the incidence decreases markedly in boys but increases in girls (23).

In the present study, we showed that among the tested antibiotics, imipenem, ciprofloxacin, and amikacin were the most active agents, whereas trimethoprim-sulfamethoxazole and cephalosporins, such as cefalotine and cephalexin, were the least active agents against E. coli isolates. The resistance rates of $E$. coli in this study were also different from those reported in similar studies among both our population and in other nations. Modarres et al. found that E. coli was most sensitive to aminoglycosides and had lowest resistance to nalidixic acid (6). In a study by Sharifian et al., E. coli was shown to be most sensitive to ceftriaxone, ceftizoxime, and cefotaxime (14). Similar to our study, Movahedian found that E. coli isolates were most susceptible to amikacin and were most resistant to cephalexin (24). In addition, another study showed the highest susceptibility to amikacin (97.8\%) and resistance to cephalexin was reported in $24 \%$ of cases (25). Other studies showed that the resistance of $E$. coli to first generation cephalosporins has increased by up to $20 \%$ in recent years (26). Based on our findings, imipenem, ciprofloxacin, and aminoglycosides, such as amikacin, are appropriate for initial empirical intravenous therapy for UTI among Iranian children, despite an increased resistance rate of E. coli isolates. Aminoglycosides are considered safe for the treatment of UTI in children and minimally impact the intestinal flora; therefore, there is a low rate of resistance against them (17). The efficacy of these drugs has been shown particularly in those who are receiving prophylactic antibiotics because of a high resistance rate to third-generation cephalosporins (8).

Our study found that nitrofurantoin had a moderate antibacterial effect against $E$. coli, with a resistance rate of approximately $60.0 \%$. However, in previous studies, nitrofurantoin was found to be very active against $E$. coli isolates, with a susceptibility rate of $96.3 \%$ to $97.8 \%(3,4,7)$. Some studies even recommended nitrofurantoin as the first choice among oral antibiotics for prophylaxis and treatment of UTI in children (27).

In the present study, imipenem was the most effective antimicrobial agent against Enterobacter, but nitrofurantoin and almost all of the cephalosporins were the least active agents against Enterobacter. Although some recent studies have shown that most Enterobacteriaceae strains were susceptible to third-generation cephalosporins (28), oth- ers found that 31\% of Enterobacter spp. infections in intensive care units were not susceptible to third-generation cephalosporins (29). In addition, a high rate of Enterobacter resistance to fluoroquinolone, beta-lactam, and cephalosporin antibiotics has been reported in European countries, South America, Asia, and Pacific regions owing to the production of extended-spectrum beta-lactamases (30). Therefore, because of its efficacy against antibioticresistant Enterobacter, imipenem is a suitable alternative therapeutic for the treatment of UTI caused by this pathogen in children.

In summary, the low susceptibility of different UTI-related isolates to nitrofurantoin and other common antibiotics, particularly broad-spectrum agents, is mainly the result of broad or inappropriate use of potent antibiotics in hospitals and changing the treatment approach without consulting a physician. Therefore, reducing the prescription of a particular antibiotic and informing patients about appropriate drug use can decrease the resistance to various antibacterial agents of common uropathogens causing UTI in children.

\section{Acknowledgments}

The authors thank the interviewers who collected the information and other individuals who dedicated their time for the study.

\section{Financial Disclosure}

None declared.

\section{Funding/Support}

This research project has been supported by Baqiyatallah University of Medical Sciences.

\section{Authors' Contribution}

Shahla Afsharpaiman, Mohammad Torkaman, and Zohreh Kavehmanesh made substantial contributions to the conception and design of this study; Suzan Amirsalari and Fatemeh Bairaghdar made substantial contributions to the acquisition of data; Mehran Moradi drafted the manuscript, and Mohammad Javad Safavimirmahalleh performed statistical analysis and data interpretation and approved the manuscript.

\section{References}

1. Al-Mardeni RI, Batarseh A, Omaish L, Shraideh M, Batarseh B, Unis $\mathrm{N}$. Empirical treatment for pediatric urinary tract infection and resistance patterns of uropathogens, in Queen Alia hospital and prince A'Isha military center--Jordan. Saudi J Kidney Dis Transpl. 2009;20(1):135-9.

2. Al-Mendalawi MD. Antibiotic resistance pattern and empirical therapy for urinary tract infections in children. Saudi Med J. 2008;29(10):1520.

3. Anatoliotaki M, Galanakis E, Schinaki A, Stefanaki S, Mavrokosta M Tsilimigaki A. Antimicrobial resistance of urinary tract pathogens in children in Crete, Greece. Scand J Infect Dis. 2007;39(8):671-5.

4. Yuksel S, Ozturk B, Kavaz A, Ozcakar ZB, Acar B, Guriz H, et al. An- 
tibiotic resistance of urinary tract pathogens and evaluation of empirical treatment in Turkish children with urinary tract infections. Int J Antimicrob Agents. 2006;28(5):413-6.

5. Mathai D, Jones RN, Pfaller MA. Epidemiology and frequency of resistance among pathogens causing urinary tract infections in 1,510 hospitalized patients: a report from the SENTRY Antimicrobial Surveillance Program (North America). Diagn Microbiol Infect Dis. 2001;40(3):129-36.

6. Modarres S, Oskoii NN. Bacterial etiologic agents of urinary tract infection in children in the Islamic Republic of Iran. East Mediterr Health. 1997;3:290-5.

7. Farrell DJ, Morrissey I, De Rubeis D, Robbins M, Felmingham D. A UK multicentre study of the antimicrobial susceptibility of bacterial pathogens causing urinary tract infection. J Infect. 2003:46(2):94-100.

8. Lutter SA, Currie ML, Mitz LB, Greenbaum LA. Antibiotic resistance patterns in children hospitalized for urinary tract infections. Arch Pediatr Adolesc Med. 2005;159(10):924-8.

9. Pena C, Albareda JM, Pallares R, Pujol M, Tubau F, Ariza J. Relationship between quinolone use and emergence of ciprofloxacinresistant Escherichia coli in bloodstream infections. Antimicrob Agents Chemother. 1995;39(2):520-4.

10. Ashkenazi S, Even-Tov S, Samra Z, Dinari G. Uropathogens of various childhood populations and their antibiotic susceptibility. Pediatr Infect Dis J.1991;10(10):742-6.

11. Panahi Y, Beiraghdar F, Moharamzad Y, Matinzadeh ZK, Einollahi B. The incidence of urinary tract infections in febrile children during a two-year period in Tehran, Iran. Trop Doct. 2008;38(4):247-9.

12. Naseri M, Alamdaran A. Urinary tract infection and predisposing factors in children. Iran J Pediatr. 2007;17(3).

13. Bauer AW, Kirby WM, Sherris JC, Turck M. Antibiotic susceptibility testing by a standardized single disk method. Am J Clin Pathol. 1966;45(4):493-6.

14. Sharifian M, Karimi A, Tabatabaei SR, Anvaripour N. Microbial sensitivity pattern in urinary tract infections in children: a single center experience of 1,177 urine cultures. Jpn J Infect Dis. 2006;59(6):380-2.

15. Farajnia S, Alikhani MY, Ghotaslou R, Naghili B, Nakhlband A. Causative agents and antimicrobial susceptibilities of urinary tract infections in the northwest of Iran. Int J Infect Dis. 2009;13(2):140-4.

16. Zhanel GG, Karlowsky JA, Harding GK, Carrie A, Mazzulli T, Low $\mathrm{DE}$, et al. A Canadian national surveillance study of urinary tract isolates from outpatients: comparison of the activities of trimethoprim-sulfamethoxazole, ampicillin, mecillinam, nitrofurantoin, and ciprofloxacin. The Canadian Urinary Isolate Study Group. Antimicrob Agents Chemother. 2000;44(4):1089-92.
17. Gupta K. Emerging antibiotic resistance in urinary tract pathogens. Infect Dis Clin North Am. 2003;17(2):243-59.

18. Hooton TM, Stamm WE. Diagnosis and treatment of uncomplicated urinary tract infection. Infect Dis Clin North Am. 1997;11(3):551-81.

19. Torkaman M, Afsharpaiman SH, Hoseini MJ, Moradi M, Mazraati A, Amirsalari S, et al. Platelet count and neonatal sepsis: a high prevalence of Enterobacter spp. Singapore Med J. 2009;50(5):4825 .

20. Tamim MM, Alesseh H, Aziz H. Analysis of the efficacy of urine culture as part of sepsis evaluation in the premature infant. Pediatr Infect Dis J. 2003;22(9):805-8.

21. Bergstrom T, Larson H, Lincoln K, Winberg J. Studies of urinary tract infections in infancy and childhood. XII. Eighty consecutive patients with neonatal infection. JPediatr. 1972;80(5):858-66.

22. Littlewood JM. 66 infants with urinary tract infection in first month of life. Arch Dis Child. 1972;47(252):218-26.

23. Stull TL, LiPuma JJ. Epidemiology and natural history of urinary tract infections in children. Med Clin North Am. 1991;75(2):287-97.

24. Movahedian AH, Mosayebi Z, Moniri R. Urinary Tract Infections in Hospitalized Newborns in Beheshti Hospital, Iran: A Retrospective Study. J Infect Dis Antimicrob Agents. 2007;24(1):7-11.

25. Pape L, Gunzer F, Ziesing S, Pape A, Offner G, Ehrich JH. [Bacterial pathogens, resistance patterns and treatment options in community acquired pediatric urinary tract infection]. Klin Padiatr. 2004;216(2):83-6.

26. Yildiz B, Kural N, Durmaz G, Yarar C, Ak I, Akcar N. Antibiotic resistance in children with complicated urinary tract infection. Saudi Med J. 2007;28(12):1850-4.

27. Randrianirina F, Soares JL, Carod JF, Ratsima E, Thonnier V, Combe P, et al. Antimicrobial resistance among uropathogens that cause community-acquired urinary tract infections in Antananarivo, Madagascar. J Antimicrob Chemother. 2007;59(2):309-12.

28. Paterson DL. Resistance in gram-negative bacteria: Enterobacteriaceae. Am J Infect Control. 2006;34(5 Suppl 1):S20-8; discussion S64-73.

29. Rossi F, Baquero F, Hsueh PR, Paterson DL, Bochicchio GV, Snyder TA, et al. In vitro susceptibilities of aerobic and facultatively anaerobic Gram-negative bacilli isolated from patients with in tra-abdominal infections worldwide: 2004 results from SMART (Study for Monitoring Antimicrobial Resistance Trends).J Antimicrob Chemother. 2006;58(1):205-10.

30. Chow JW, Satishchandran V, Snyder TA, Harvey CM, Friedland IR, Dinubile MJ. In vitro susceptibilities of aerobic and facultative gram-negative bacilli isolated from patients with intra-abdominal infections worldwide: the 2002 Study for Monitoring Antimicrobial Resistance Trends (SMART). Surg Infect (Larchmt). 2005;6(4):439-48. 